\title{
Methods for Translating Narrative Scenarios into Quantitative Assessments of Land Use Change
}

\author{
Varun Rao Mallampalli ${ }^{1}$, Georgia Mavrommati ${ }^{2}$, Jonathan Thompson ${ }^{3}$, Matthew Duveneck ${ }^{4}$, Spencer \\ Meyer $^{5}$, Arika Ligmann-Zielinska ${ }^{6}$, Caroline Gottschalk Druschke ${ }^{7}$, Kristen Hychka ${ }^{8}$, Melissa A. \\ Kenney $^{9}$, Kasper Kok ${ }^{10}$, Mark E. Borsuk ${ }^{11}$
}

\begin{abstract}
In the land use and land cover (LULC) literature, narrative scenarios are qualitative descriptions of plausible futures associated with a combination of socio-economic, policy, technological, and climate changes. LULC models are then often used to translate these narrative descriptions into quantitative characterizations of possible future societal and ecological impacts and conditions. To respect the intent of the underlying scenario descriptions, this process of translation needs to be thoughtful, transparent, and reproducible. This paper evaluates the current state of the art in scenario translation methods and outlines their relative advantages and disadvantages, as well as the respective roles of stakeholders and subject matter experts. We summarize our findings in the form of a decision matrix that can assist land use planners, scientists, and modelers in choosing a translation method appropriate to their situation.
\end{abstract}

Keywords: socio-ecological scenarios, participatory process, agent-based model, fuzzy cognitive map, Bayesian network, system dynamics

1 PhD Candidate, Thayer School of Engineering, Dartmouth College, Hanover, NH, USA

2 Post-Doctoral Associate, Environmental Studies Program, Dartmouth College, Hanover, NH, USA

3 Senior Ecologist, Harvard Forest, Harvard University, Petersham, MA, USA

${ }^{4}$ Post-Doctoral Fellow, Harvard Forest, Harvard University, Petersham, MA, USA

${ }^{5}$ Post-Doctoral Associate, Yale School of Forestry and Management, New Haven, CT, USA

6 Associate Professor, Department of Geography and Environmental Science and Policy Program, Michigan State University, East Lansing, MI,USA

7 Assistant Professor, Department of Natural Resources Science, University of Rhode Island, Kingston, RI, USA

8 Post-Doctoral Fellow, Department of Natural Resources Science, University of Rhode Island, Kingston, RI, USA

9 Assistant Research Professor, Earth System Science Interdisciplinary Center, University of Maryland, College Park, MD,USA

${ }^{10}$ Assistant Professor, Environmental Sciences, Wageningen University and Research Centre, Wageningen, Netherlands

${ }^{11}$ Associate Professor, Thayer School of Engineering, Dartmouth College, Hanover, NH, USA

Page 1 of 32 


\section{Introduction}

Anticipating environmental impacts associated with future land use is an important challenge within regional global change science. However, because land use is a product of complex socio-ecological factors, accurately predicting the drivers of land-use change, let alone future land-use patterns, is typically impossible. Therefore, analyses of future land use often take a scenario approach, wherein several potential pathways are examined without an attempt to make precise or probabilistic predictions; rather, a range of possibilities are considered. In this sense, scenarios are "coherent and plausible stories, told in words and numbers, about the possible co-evolutionary pathways of combined human and environmental systems" (Swart et al., 2004). The creation and analysis of land-use scenarios allows practitioners to integrate diverse modes of knowledge and to explicitly recognize those components of complex systems that are uncertain (Thompson et al., 2012). Consequently, land use scenarios are a ubiquitous component of integrated environmental assessments at global (Alcamo, 2009), regional (Sleeter et al., 2012), and local (Carpenter et al., 2015) scales.

Scenarios take many forms and vary widely in terms of how they are developed. One useful distinction is between qualitative and quantitative scenarios (Alcamo, 2009). Qualitative land-use scenarios are nonnumerical descriptions of the way the future may unfold depicted as narrative texts or storylines. Done well, qualitative scenarios offer a compelling vision that showcases the myriad consequences and interdependencies of alternative land-use decisions. Developing qualitative scenarios can be useful for generating ideas and strategies and for incorporating multiple viewpoints without requiring specific technical expertise. As such, the process of constructing scenarios can bridge gaps between and among experts, decision-makers, and stakeholders (Welp et al., 2006). Participatory scenario development is increasingly used to ensure that a range of viewpoints and expertise is captured by qualitative storylines and to maximize the legitimacy and salience of the research for decision makers (Cash et al., 2002; Seppelt et al., 2011).

Quantitative land-use scenarios, in contrast, describe plausible futures using numerical descriptions of one or more of the rates, types, and spatial allocations of land uses associated with a potential pathway. Quantitative scenarios are typically designed to support numerical assessment of specific impacts. In many cases, quantitative scenarios are derived using spatially explicit simulation models of land use and land-cover change, often coupled to models of ecosystems, hydrology, or other affected components of the environment. Accordingly, the information required for the quantitative scenario is often specific and technical, thus confining the process to scientific experts. This runs the risk of excluding non-technical viewpoints and can decrease the accessibility of results to non-experts (Voinov and Bousquet, 2010). 
Often the value of scenario planning can be maximized when the inclusivity and creativity of qualitative scenarios is coupled with the specificity of quantitative modeling. Indeed, coupled qualitative and quantitative scenarios are the basis of many prominent scenario assessments in domains not directly related to land use assessment, such as the IPCC Special Report on Emission Scenarios (Nakicenovic and Swart, 2000) and the Millennium Ecosystem Assessment (Millennium Ecosystem Assessment, 2003). To date, the story and simulation (SAS) approach has been most commonly used to couple qualitative and quantitative scenarios. In this approach, scenarios are first defined by experts and/or stakeholders and subsequently translated into quantitative parameters that feed into simulation models (Alcamo et al., 2008; Houet et al., 2016). As shown in figure 1, this may be an iterative process such that narrative scenarios are translated into quantitative models that are then used to revise or enrich storylines based on the particular simulation results.

Ultimately, any modeling approach used requires a "translation" step to relate qualitative narrative scenarios to specific simulation model formulations and input values. This translation needs to adhere to the assumptions and interactions contained in the narrative, while also being compatible with the level of complexity of the chosen model (Kok, 2009). In this paper, we review the state-of-the-art of methods used to perform such translation for future land-use scenarios. Our effort was initiated as part of a recent workshop organized by the Scenarios, Services, and Society Research Coordination Network ( $\mathrm{S}^{3} \mathrm{RCN}$; s3rcn.org) funded by the U.S. National Science Foundation. Based on a review of the land use and land change (LULC) scenario literature, we outline the relative advantages and disadvantages of the various translations methods. Many of these methods can also be used in the original construction of the narrative scenario and/or in the model-based scenario quantification. Finally, we provide a decision matrix summarizing our findings that can assist land use planners, scientists, and modelers in choosing a translation method appropriate to their situation. 


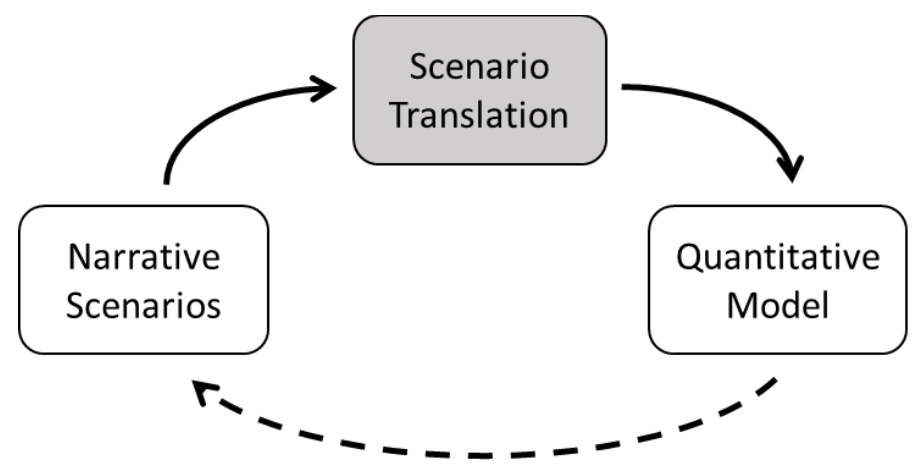

Figure 1: Scenario development process. Dashed arrow indicates that scenario development can be an iterative process. The present paper addresses mainly the narrative translation step (grey box).

\section{Translation Methods}

We review ten methods that can be used to translate between narrative scenario descriptions and quantitative simulation models. We evaluate each method according to the underlying conceptual foundation, treatment of uncertainty, potential to accommodate stakeholder participation, relative level of resources required, and compatibility with common simulation models. Table 1 provides a summary, including references to example applications. We also evaluate the relative advantages and disadvantages of each method in particular applications. These criteria are further elaborated in the discussion section and are summarized in the form of a decision matrix (Table 2). The purpose of this matrix is to assist scenario developers and modelers in the choice of an appropriate translation method for their particular situation.

\subsection{System Dynamics}

\subsubsection{Use in Translation}

System dynamics (SD) is a method for framing and disentangling the non-linear behavior of complex systems over time (Schmitt Olabisi et al., 2010). SD acknowledges that mental models are typically unable to capture features of complex systems such as feedback loops, time delays and policy resistance (Sterman, 2012). SD uses graphical causal loop diagrams (Ford, 1999) to represent cause and effect relationships and feedbacks. When used to represent human-environment interactions, the SD method has the potential to engage stakeholders in the process of understanding dynamics and defining scenarios (Mavrommati et al., 2014; Schmitt Olabisi et al., 2010; Yu et al., 2011). 
The SD approach can be used for qualitative-to-quantitative scenario translation either directly or indirectly. In the direct method, researchers and stakeholders work together to understand the system under study by: (i) identifying relationships among the system's key components and leverage points and then (ii) jointly exploring plausible scenarios. This SAS-type approach typically first yields an initial causal loop diagram corresponding to a business-as-usual scenario, which corresponds to a future scenario if no changes are made to the system. This process can then be used to generate additional scenarios by exploring relevant modifications (Mavrommati et al., 2014).

In the indirect method, the scenario development process precedes the development of a causal loop diagram. For example, the Minnesota 2050 project (Schmitt Olabisi, Kapuscinski et al. 2010) used scenario visioning and stakeholder participatory modeling to develop narrative scenarios describing cause-effect relationships. Researchers then used these qualitative scenarios to identify the system variables, linkages, and underlying assumptions necessary to create a causal loop diagram (Figure 2). Stakeholders then had the opportunity to provide their comments on the diagram at a follow up meeting. Numerical implementation of a causal loop diagram requires conversion to a stock-flow model along with additional parameterization. In the case of the Minnesota 2050 project, empirical data were used to parameterize the model with a range of values employed to explore various scenarios.

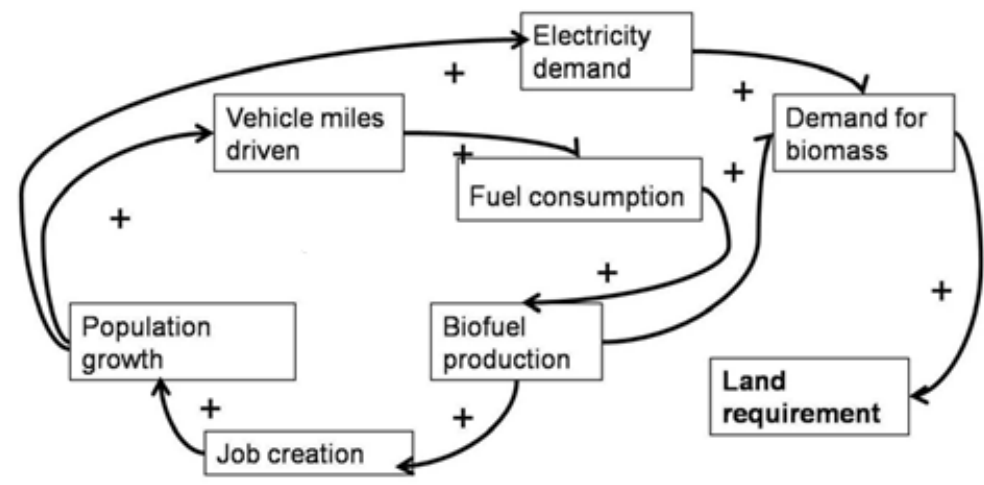

Figure 2. A causal loop diagram from the Minnesota 2050 project where the main focus was on the interactions between energy demand, fuel type, and land use. Positive (+) arrows represent a cause-andeffect relationship in which the two variables change in the same direction. The existence of a positive feedback loop on the left side of the diagram indicates that changes in any of these variables are reinforcing. Reproduced from Schmitt Olabisi et al., 2010. 


\subsubsection{Advantages and Disadvantages}

Applying SD methodology to scenario narratives can shed light on inconsistencies, provide a numerical representation of scenarios, and allow the consideration of unexpected events that are difficult to model otherwise (Schmitt Olabisi et al., 2010). Its application can be extended to both narrative construction and scenario quantification. In terms of scenario purpose, it finds greatest use in the evaluation of top-down policy choices and prescriptive actions. The SD method can also: (i) integrate multiple stakeholders, experts, disciplines, processes, and policy prescriptions, and (ii) identify leverage points for policy making (Kelly et al., 2013). Stakeholders and experts can easily be engaged in a collaborative workshop setting to use this method. Further, with available software, modelers can create a user-friendly interface that enables stakeholders to run their own scenarios. For example, users can typically adjust model parameters through drop-down menus or "sliders."

The main disadvantage of the SD method is the frequent inability to ensure the numerical accuracy of outputs, either because of the potential for faulty assumptions or the lack of available data for validation. Therefore, using SD as a translation method is most suitable when the purpose is to understand the possibility of dynamic changes and unintended consequences, rather than to predict precise model outputs for specific system variables.

\subsection{Fuzzy Cognitive Maps}

\subsubsection{Use in Translation}

Fuzzy Cognitive Maps (FCMs) were first developed by Kosko (1986) as a means to map and quantify fuzzy relationships between system variables. Although originally introduced as a tool for analyzing uncertainties in relationships and the resulting effects on system behavior, many recent applications have emphasized the use of FCMs as a systems-thinking approach. In this capacity, it is particularly applicable to scenarios that are characterized by multiple co-evolving drivers in which the objective is to understand system resilience to change (Diniz et al., 2015; Gray et al., 2015; Kok, 2009). Kosko (1986) explains that FCMs are especially appropriate for exploring causality when the knowledge domain is soft; that is, when both the variables of the system and their relationships are fundamentally fuzzy. As a means for representing qualitative beliefs about the current or future state of a system, FCMs are relevant to land use scenario planning and analysis (Jetter and Kok, 2014; Kok, 2009). They can be applied to problems at different geographical scales, from local to global (Jetter and Kok, 2014), and thus can be useful for exploring a variety of policy measures and their implications for the social-ecological resilience of systems. This makes them a potentially valuable tool for policy makers. 
In their role as a translation tool between qualitative scenarios and quantitative models, FCM construction begins by identifying the drivers of change described in the narratives and mapping the drivers and relationships between them. Just as in the system dynamics approach, diagrams are constructed for this purpose. The translation can be done by experts alone or in combination with stakeholders; however the biggest advantages result from stakeholders concurrently developing narratives and their FCM representations (van Vliet et al., 2010). Structured, quantitative surveys can help establish parameters defining the strength of relationships between drivers (van Vliet et al., 2010). Respondents start with signs to indicate causality ( + or - ) and then assess the strength of the causality starting with a subjective scale that is subsequently translated into 0 to 1 weights (Figure 3 ).

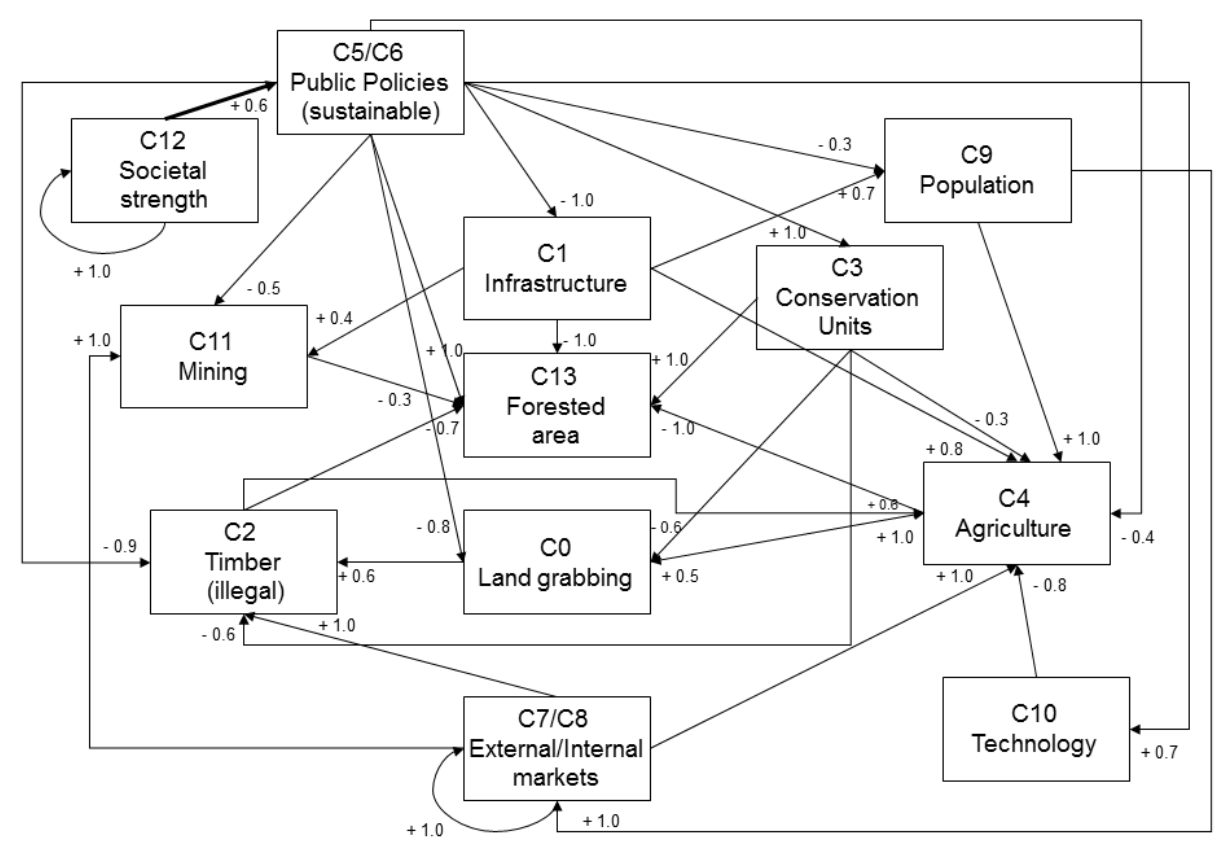

Figure 3: An FCM developed to describe the system of drivers of deforestation for the Brazilian Amazon as developed by stakeholders. (Adapted from Kok 2009.)

\subsubsection{Advantages and Disadvantages}

Similar to the SD methodology, the main advantages of FCM are its ability to: (i) lucidly represent a complex system and provide insight on feedbacks; (ii) provide scenario enrichment through concurrent development of narratives and their FCMs with stakeholders; and (iii) explicitly represent drivers and model assumptions (Kok, 2009). It can also be explained to stakeholders easily, making it particularly useful when time and resources are a constraint, and has the ability to allow users to be creative through high level integration while still requiring concrete semi-quantitative information (Kok, 2009). Like the 
SD methodology for scenario purpose, it finds greatest use in evaluating top-down policy choices and prescriptive actions.

The largest disadvantage of FCM is that relationships are semi-quantified, thus also providing only a semi-quantitative output from simulating an FCM. Another disadvantage is that the output shows values of drivers as a function of number of iterations and not as a function of time, though, according to Kok (2009), this drawback can be partly overcome by including processes that act at approximately the same time scale. Further, significant data processing may be required to un-normalize the relationships to make the data amenable to use in other simulation models. Lastly, a limitation of the method may be its need to be performed in a workshop setting. FCMs lose their salience when constructed independently.

\subsection{Agent-Based Modeling}

\subsubsection{Use in Translation}

In the LULC literature, agent-based modeling (ABM) is defined as a discrete-event simulation composed of heterogeneous and autonomous decision making entities (called 'agents') that interact with each other and act upon their shared land use environment (Ligmann-Zielinska and Jankowski, 2007; Parker et al., 2003). Agents process information derived from a changing environment and use it to make decisions about their actions (Janssen, 2005; Parker et al., 2003). These actions have an effect on land use and on the behavior of other agents in the system. Constructing an ABM for LULC first requires a qualitative content analysis step that includes the identification of agents, their attributes and actions, and the environment. This is followed by what we refer to as the "translation" step: the construction of a causal diagram that depicts the major agent interactions and system processes leading to land-use change (Figure 4). This translation can be performed with stakeholders, who may represent the different actors in the system, and can benefit from the use of the ARDI (Actors-Resources-Dynamics-Interactions) technique (Etienne et al., 2011). The translation can also be performed in combination with one or more of the other translation methods highlighted here (e.g., role playing games, pairwise comparison, and/or questionnaire surveys and interviews). These methods lead to the characterization of behavioral rules as well as the necessary inputs to the simulation model.

\subsubsection{Advantages and Disadvantages}

The major advantage of the ABM method is its ability to more faithfully represent the decision processes of many agents and then assess the effects of their micro-scale actions and interactions on macro-scale phenomena (Parker et al., 2008). It is therefore particularly suitable for evaluating lower-level actions and their anticipated outcomes. While ABMs can also be used for evaluating top-down policy choices and prescriptive actions, other methods like SDs and FCM might be more easily used for this purpose, thus 
avoiding the need to embrace unnecessary complexity. The use of other complementary methods can allow construction of narrative scenarios and model quantification. ABM is often used in companion modeling approaches to serve as a social learning tool, helping stakeholders to understand the impacts of their actions on the future of the land (Barreteau et al., 2003; Bousquet et al., 1999). Further, the engagement of local stakeholders in the construction and use of the simulation tool can help facilitate the emergence of collective plans and actions, and thus the method finds great use in a collaborative workshop setting with experts and stakeholders.

The major criticism of the ABM methodology lies in the complexity associated with modeling multiple decision making agents within the context of a complex human-natural environment (Parker et al., 2002). This limits the use of method to evaluating anticipated outcomes associated with lower-level actions. Detailed quantitative and qualitative information is often required to parameterize the model, and such information may be lacking at the relevant spatial scales (Kelly et al., 2013; Le Page et al., 2014). This lack of data can also create a problem for model validation. Further, the methodology by itself finds best use when performed in a collaborative setting with stakeholders and experts. This is a necessity as the methodology may be hard for stakeholders to understand. While the ABM methodology can be used independently, this poses a great challenge especially when it comes to characterization of behavioral rules and determination of other model inputs. 


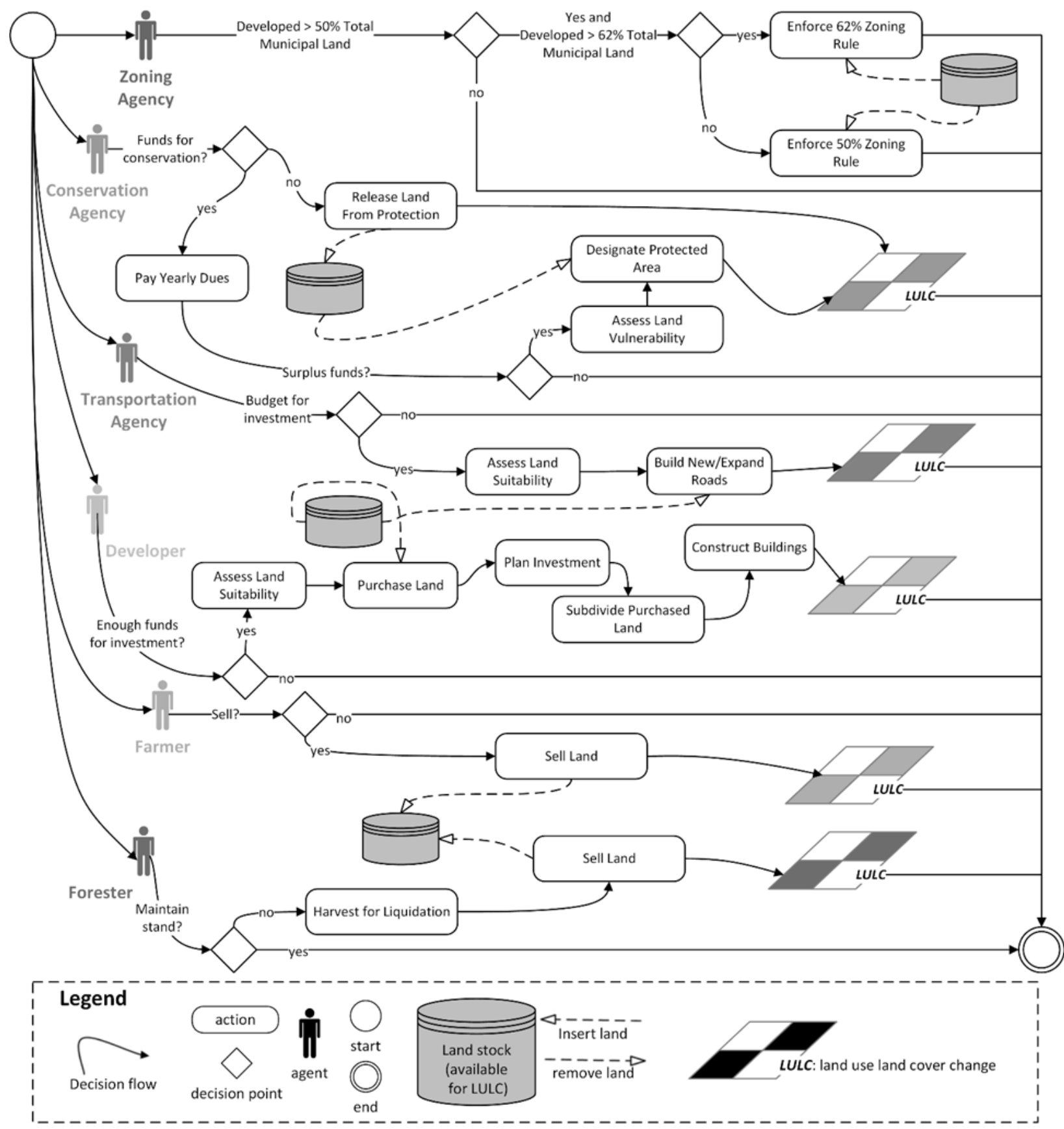

Figure 4: An overview of an ABM-based translation framework, assuming that the focus of the model is on land use composition and configuration, producing output LULC maps at different time steps of model execution. 


\subsection{Fuzzy Sets}

\subsubsection{Use in Translation}

The fuzzy sets translation method has its roots in fuzzy set theory, which was first proposed by Zadeh (1965). Zadeh (1965), and later Goguen (1969), proposed to study fuzziness contained in human language by using a mathematical construct that extended the general notion of a set. In theory, such a construct lends itself very well to translating narratives to simulation model inputs that are quantitative in nature. Fuzzy set theory has found wide application in many areas of environmental science (Cornelissen et al., 2001; Geyer-Schulz, 1995) and was used in translation for land use assessment by Alcamo et al. (2008) and Onigkeit et al. (2007) as part of the Glowa Jordan River scenario exercise. Based on these experiences, further applications included work in multiple case studies in Europe (Kok et al., 2015). Like FCMs, the fuzzy sets method provides a mathematical approach for studying vague conceptual phenomena (Zimmermann, 2010). Significant work has also been done on mapping and geovisualization of fuzzy sets (Ahlqvist, 2004; Lucieer and Kraak, 2004). Fuzzy sets are also applicable to problems that span across various scales. However, they have typically been applied to problems at a global scale when there are a large number of interacting drivers of change, thus making their translation through a systems thinking approach complicated and time consuming.

According to Alcamo (2009) there are five steps involved in translating storylines to model inputs using fuzzy sets: (i) make subjective statements about rates of change of all important drivers; (ii) derive a translation key that allows subjective statements to be translated into numbers; (iii) combine the obtained set of numbers into a membership function; (iv) use membership functions directly by linking with probability density functions or defuzzifying the output to obtain inputs for simulation models; and (v) use the outputs of simulation models to enrich storylines..

\subsubsection{Advantages and Disadvantages}

The most important advantage of this method is that stakeholder knowledge can be used for direct model parameterization, without the need for interpretation. In terms of scenario purpose, fuzzy sets are best used when the overall goal is to evaluate top-down policy choices and prescriptive actions. Other advantages include the ease with which fuzzy sets can be integrated into the scenario development process and its usefulness when performed in a collaborative setting. Stakeholders using fuzzy sets can easily be involved not just in the process of translation but also in model parameterization, and their input is especially valuable in situations in which drivers of change are directly influenced by stakeholder choices. In many situations, subjective scales along with membership functions are used to facilitate 
translation. The membership functions allow scenario developers an easy way to convert between quantitative model variables and linguistic statements in a reproducible manner.

The major disadvantage of the fuzzy set method is that it focuses solely on quantifiable parameters. This leads to its inability to incorporate feedbacks and structural relationships in the narrative. It finds almost no use in narrative construction, and relies on its use in a collaborative workshop atmosphere, thus limiting its use in an independent setting. Also, a test for scenario consistency can only be performed after running the associated simulation model. Further, membership functions do not fully quantify all aspects of the narrative, and fail to take into account "softer" drivers of change (e.g., cultural identity).

\subsection{Pairwise Comparison}

\subsubsection{Use in Translation}

The pairwise comparison method was first used in the evaluation of scenarios by Saaty and Rogers (1976). Their approach allows verbal judgments of experts to be translated into a numerical scale. Further development led to the addition of the analytic hierarchy process which allows ranking of judgments of relative importance (Saaty, 1980). More recently, the pairwise comparison approach has found applicability in agricultural land-use scenario analysis (Abildtrup et al., 2006). This methodology allows translation of qualitative beliefs into quantitative inputs for simulation models by following a simple relative ranking procedure and eigenvector calculation (Rosato and Giupponi, 2003). Like fuzzy sets, the applicability of pairwise comparison stretches across various geographical scales but is typically more useful for global or regional problems in which the set of objectives are broader than those justifying a SD approach.

The Pairwise Comparison process follows four steps: (i) subjective pairwise comparison for each driving force or parameter across all scenarios; (ii) translation of subjective measures into numerical values using the scales proposed by Saaty (1980); (iii) evaluation of the consistency of translation; and, if consistent, (iv) derivation of eigenvectors for each driver (Rosato and Giupponi, 2003). An appropriate scale must be pre-determined for each driver, and is usually based on the judgment of scenario builders. A general rule that can be followed is that the choice of scale should depend on the expected effect of a particular driver on the outcome of the scenario: the smaller the anticipated effect, the smaller the scale range (Abildtrup et al., 2006). Historically, this method has been employed only with experts and is considered an expertjudgment technique (Abildtrup et al., 2006). However, stakeholders have been involved in translation, especially in the phase of ranking drivers across scenarios (Strager and Rosenberger, 2006). The numerical evaluations and consistency checks for judgments can be performed with an available software tool. Abildtrup et al. (2006) provide a detailed example of the implementation of the method. 


\subsubsection{Advantages and Disadvantages}

The major advantage of this method is that it can be easily understood by experts coming from diverse backgrounds, as the mathematical construct is fairly simple to grasp (Saaty, 1980). Like fuzzy sets, the method finds greatest use when used when the scenario purpose is to evaluate top down policy choices and prescriptive actions. Further, it explicitly involves a consistency check to evaluate experts' judgments (Abildtrup et al., 2006). An inconsistency could hint at vagueness in narrative descriptions and the need to enrich certain aspects of scenarios. The outputs from the model can directly inform simulation models. The method is really easy to understand, and can be performed directly with stakeholders.

The disadvantage of the method is that it does not offer a robust way to check consistency across narrative scenarios. It offers little help in the construction of narrative scenarios and relies on its use in a collaborative setting. Further, the scale must be pre-determined and is based completely on the judgment of the scenario developers (Abildtrup et al., 2006). The process can also be time-consuming, especially when working through various combinations in trying to achieve consistency across experts (Abildtrup et al., 2006).

\subsection{Bayesian Statistical Reasoning}

\subsubsection{Use in Translation}

Bayesian statistical reasoning as applied to scenario translation (Kemp-Benedict, 2010) has its foundations in Bayes' rule of conditional probability. According to Bayes' rule, the posterior distribution of a particular model parameter $z$, given a particular scenario $S$, is written as:

$P(z \mid S) \propto P(S \mid z) P(z)$

where $\mathrm{P}(z)$ is a prior probability specifying the distribution for the parameter in a reference case, and $\mathrm{P}(S \mid z)$ is a conditional probability, which can be thought of as a measure of the degree of confidence that scenario $\mathrm{S}$ is occurring given information on the value of $z$.

The translation process thus begins by specifying prior distributions for each of the parameters in the reference case, which can be a baseline or a business-as-usual scenario (Kemp-Benedict, 2010). Historical data are generally used as the basis for the reference case, and stakeholder or expert elicitations can be used to construct prior distributions that reflect the range of beliefs (Kemp-Benedict, 2010). The next step is to evaluate the conditional probability $\mathrm{P}(S \mid z)$ based on the knowledge and experience of stakeholders and experts. The posterior distribution of each parameter under each scenario can then be evaluated from eq. (1), often with the aid of available software (Kemp-Benedict, 2010). 


\subsubsection{Advantages and Disadvantages}

The major advantage of this method is the ease with which it can be implemented in a workshop setting with experts. A software program can be used to quickly calculate posterior parameter distributions. Depending on the simulation model used, these distributions can then be used directly to represent uncertainty. If the simulation model is not compatible with stochastic inputs, then posterior means might be used as inputs. In terms of the scenario purpose, it's best used for evaluating top down policy choices and prescriptive actions.

The major disadvantage of this method is in its limited applicability with stakeholders. Some understanding of the ideas of probability and likelihood distributions is necessary, though experts may be able to design the translation process in a way that facilitates stakeholder engagement. The method also has limited applicability in understanding feedbacks or testing narrative consistency, and is constrained in its ability to quantify or represent the softer drivers of change in the narrative. It offers limited extensibility in terms of narrative construction.

\subsection{Bayesian Network}

\subsubsection{Use in Translation}

The idea of constructing graphical influence diagrams and then populating them with conditional probability tables to develop Bayesian networks (BN) was first formalized by Pearl (1985). Pearl (1985) constructed a BN with the goal of devising a computational model for making inferences about human reasoning. In the field of land use change, participatory modeling approaches with BNs have explored the role of stakeholders as information providers in the absence of empirical data to define conditional probability tables, as well as in the construction of the influence diagrams themselves.

A BN consists of two key components: (i) an influence diagram that describes underlying relationships in a system and (ii) a set of conditional probability tables, which define the quantitative relationships between each variable and its parents. Together, these components decompose a complex causal chain into a series of local relationships. These relationships can be characterized using variety of sources including stakeholder beliefs, experts, and literature review (Barton et al., 2012; Marcot et al., 2001). The final nodes describing the land use outcome are generated by propagating uncertainty through the network using probability calculus or available simulation software (Aalders, 2008; Meyer et al., 2014). These outputs can then feed into more detailed simulation models (e.g., cellular models of land use change). Since the outcome of the $\mathrm{BN}$ is the land-use change phenomena researchers are interested in, the translation step can be defined as the construction of the influence diagram and specification of conditional probabilities that drive land use change. 
In one recent application of BNs to land use change, researchers in Maine, USA, developed a framework for using BNs with a cellular automata model to translate stakeholder-derived qualitative scenarios of land use change into quantitative, spatially explicit future land use simulations (Figure 5) (Meyer et al., 2014). The BNs, which provided pixel-level suitability assessments (Figure 6), were used as input into the cellular automata model, which applied pixel and patch-level transitions based on stakeholder-derived future scenarios. Using results from this study, land managers and policy makers were able to: (i) identify high-value conservation, economic development, and natural resource assets; (ii) evaluate potential current and future conflicts and opportunities between land uses; and (iii) envision the impacts of alternative policy decisions on future land use, both at the local- and landscape-levels.

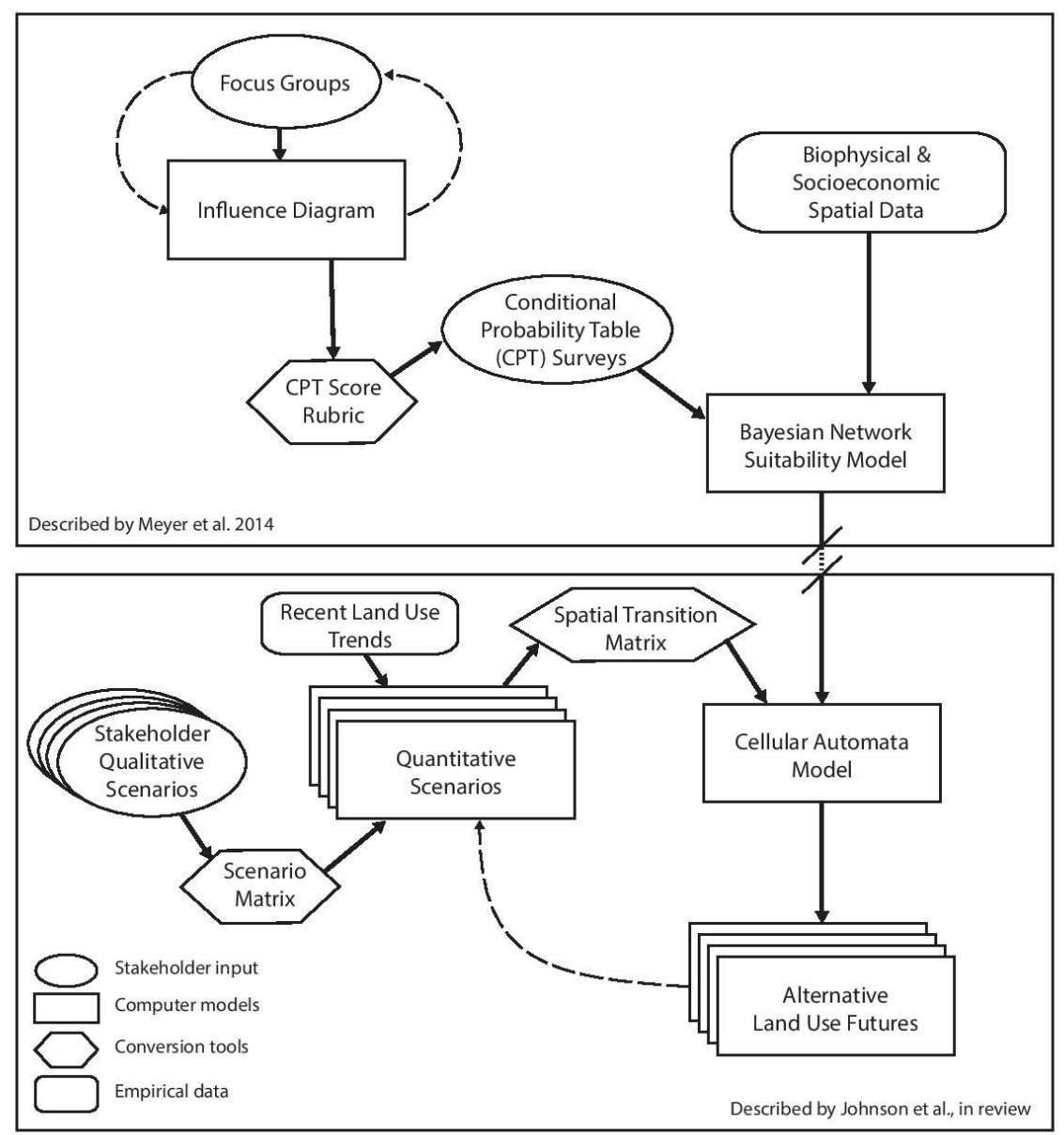

Figure 5: Schematic of an integrated Bayesian network/cellular automata land use scenario model (Meyer et al., 2014). 


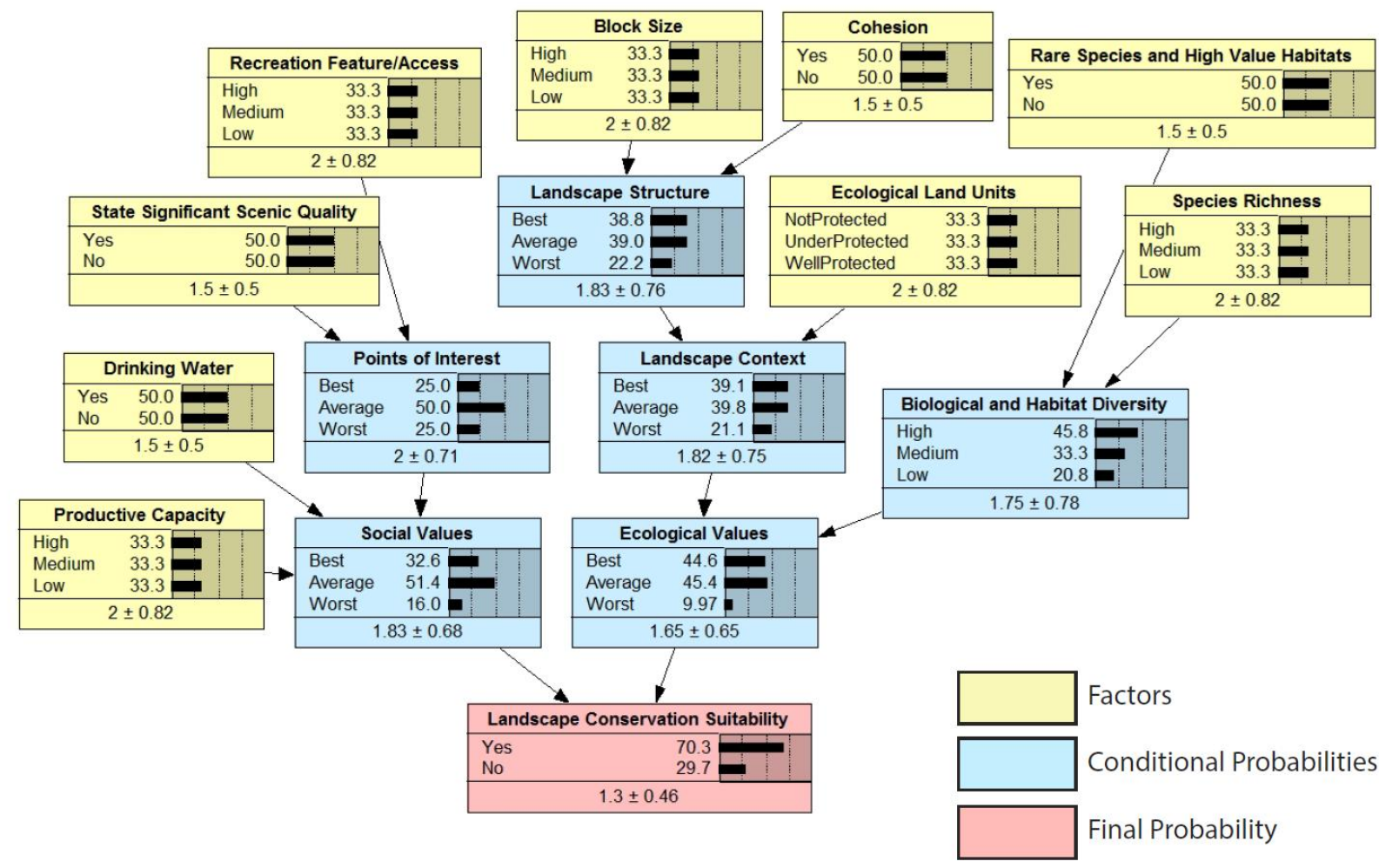

Figure 6: One of the Bayesian network diagrams of Meyer et al. (2014) used to assess landscape conservation suitability. In this example, specific findings have been entered for each factor to show the overall probability of suitability based on those inputs (Meyer et al., 2014).

\subsubsection{Advantages and Disadvantages}

The major benefits of the $\mathrm{BN}$ approach are the ability to rapidly update model outputs as new data become available and the ability to re-calibrate the model to a different set of stakeholder inputs (e.g., translation and application to another study area). In terms of scenario purpose, it is valuable in evaluating top-down policy choices and prescriptive actions; but can also offer some insight into the anticipated outcomes of certain lower-level actions. Other advantages lie in its ability to combine different sources of knowledge, including expert as well as stakeholder beliefs (Borsuk et al., 2004; Marcot et al., 2006; Uusitalo, 2007). This also makes BNs suitable for applications where data are incomplete. This is especially valuable for land use change applications, as land use data often contain missing values. The outputs from influence diagrams and conditional probability tables can inform not just BN but also cellular models where transitions (e.g., in land use change) are based on probabilities. BNs can thus be used for developing quantitative assessments for model-based inputs. 
The disadvantages of $\mathrm{BN}$ lie in the process of translation with stakeholders and experts. It may be difficult to obtain information in the form of conditional probabilities, especially if stakeholders have difficulty conceptualizing the idea of conditional distributions (Morgan et al., 1992). This can be overcome if the translation process is carefully designed to solicit relevant stakeholder knowledge. Further, BN are most often used to study specific systems or sub-systems and a specific change associated with the system. If narratives describe multiple land use changes, BN modeling of all the changes can be a tedious task. Further, BNs fail to account for feedbacks in the system, being acyclic in structure (Jensen, 2001). Several networks can be constructed to model temporal and spatial dynamics of feedback; however, this task may prove to be tedious (Jensen, 2001). While BNs can be constructed independently, it is difficult especially when it comes to assessing conditional probability distributions.

\subsection{Role Playing Games}

\subsubsection{Use in Translation}

Role Playing Games (RPGs) can be defined as "the performance of an imaginary or realistic situation played by people with given roles in order to analyze behavioral patterns" (Shaftel and Shaftel, 1967). RPGs can be used to create narratives, identify drivers of change, and parameterize simulation models for coupled human and natural systems (Castella et al., 2005; Pak and Brieva, 2010; Washington-Ottombre et al., 2010). Role playing games were used in land-use management and planning by Commere (1989). Since then, they have gained popularity in the field of land-use change and have been employed as a social learning and collective management tool (Castella et al., 2005; Dumrongrojwatthana et al., 2011; Souchère et al., 2010). Stand-alone RPGs have been used to investigate the results of stakeholder actions on land-use change by generating maps of the future, and in mediating negotiations in ecological systems that require resource sharing (Dung et al., 2009; Pak and Brieva, 2010). More recently, role playing games have been used to parameterize agent based models by identifying specific drivers of change (Castella et al., 2005; Le Page et al., 2014; Washington-Ottombre et al., 2010). Lamarque et al. (2013) used role playing games to create quantitative maps of land use change from qualitative storylines and descriptions of farmers' decision making.

The use of RPG in translation is most compatible with agent-based and multi-agent simulation models, given the ability of both to model individual behavior (Barreteau et al., 2001; Bousquet et al., 1999). The translation process begins with the co-creation of a game with heterogeneous stakeholders that represents the baseline scenario to be explored (D'Aquino et al., 2002). This is followed by identification of alternate scenarios using a modified version of the RPG or a computer ABM. It is important to identify relevant stakeholders to create a game that appropriately simulates a real-world representation of their roles and 
responsibilities. When stakeholders are used to construct alternate scenarios, the basic game needs to be modified to accommodate their proposed changes. A game consistent across all scenarios can be generated with variable constraints and decision rules based on the scenarios. Stakeholder actions during the game can be interpreted as inputs to simulation models or can serve to create stand-alone quantitative maps of land-use change (D'Aquino et al., 2002; D'Aquino et al., 2003). Usually, a series of successive versions of the game are used with stakeholders not just to simulate various proposed scenarios but also to facilitate social learning, consensus building, and objective exploration. While the type of game created varies depending on the system being studied, some standard role playing games exist in the literature and have been adapted for various applications in land use change (Campbell and Palutikof, 1978; Meadows et al., 1989).

\subsubsection{Advantages and Disadvantages}

The biggest advantage of RPGs is the ability to accommodate the range of behaviors, decision-making, and adaptation through direct involvement of stakeholders (Lamarque et al., 2013). Narrative descriptions are easily communicated through the medium of a game to stakeholders and the uncertainty inherent in narrative descriptions is easily accommodated (Lamarque et al., 2013; Martin et al., 2011). It is therefore useful to be used as a narrative construction tool. RPGs offer an easy way to understand the individual behavioral drivers that contribute to land management change (Naivinit et al., 2010; Pak and Brieva, 2010). It is an effective tool for social learning by fostering the exchange of knowledge between land users and scientists (Barnaud et al., 2010; Dumrongrojwatthana et al., 2011; Martin et al., 2011). Model validation can be performed in several ways such as statistical analyses, interviews with stakeholders, and by consulting experts on proposed adaptations (Castella et al., 2005; Lamarque et al., 2013; WashingtonOttombre et al., 2010). In terms of scenario purpose, it is especially useful when used to evaluate lowerlevel policy choices and their anticipated outcomes, given the focus of the method on the human behavior and its outcome.

Despite these advantages, the method can be extremely demanding in terms of resources and time commitment. The success of the method hinges on the degree of engagement of stakeholders and the quality of knowledge and information exchange, as well as the compatibility of the method with simulation tools. Engaging stakeholders can be a challenging task if the rules of the game are difficult to understand. Further, it is important that RPGs adequately represent aspects of a scenario, stimulate user creativity, and provide information on behavioral drivers of change while also ensuring that the RPGs represent stakeholders' views of reality, and not their views on making an interesting game. Several runs may be necessary to achieve results that are consistent and repeatable. 


\subsection{Other Methods}

There are other, less-formal methods of translating scenario narratives into quantitative models, including questionnaire surveys, semi-structured interviews, and literature reviews. Surveys and semi-structured interviews are surveys of subjective beliefs of experts or stakeholders, and can allow limited stakeholder engagement while providing direct input for the simulation model (McDaniels et al., 2012). These can also be conducted in a structured way using a Delphi method within the context of a workshop (Dubrovsky et al., 2011). Literature review is probably the most common additional approach and is often conducted by the modeler using his or her interpretation of the narratives. This method limits engagement with stakeholders and tends to be heavily influenced by existing data and model studies (Dubrovsky et al., 2011).

\section{Discussion}

Moving from narrative scenarios to a quantitative model-based assessment of land use change requires an approach that faithfully characterizes the original narratives and is reproducible and internally consistent. For this reason, LULC modelers may want to follow an established approach, rather than relying on their own independent, and often ad-hoc, judgment. With this in mind, we aim to facilitate the choice of approach by revisiting the methods reviewed above according to four practical considerations (Table 2): (i) purpose of the scenario process, (ii) potential to extend the approach to include narrative creation and/or quantitative modeling, (iii) type of participation desired, and (iii) type of compatible simulation model. We describe each of these considerations and our basis for scoring the approaches below.

\subsection{Scenario Purpose}

The choice of a model and/or translation method should be strongly influenced by the level of analysis necessary in the scenario development process. Key developments in both the biophysical and socioeconomic aspects of the considered scenarios may occur at either state/regional/national level or at the field/community level (Castella et al., 2007). Similarly, policy questions being asked of the analysis may pertain to either top-down policy actions and prescriptions, or lower-level actions and anticipated responses to policy. The 'top-down' emphasis is appropriate when land use changes are largely determined by exogenous forces, such as changes in global demand and market conditions (Verburg and Overmars, 2009). A 'bottom-up' or lower-level perspective is needed when changes are the result of local land ownership and the corresponding management decisions being made. Hybrid cases may also exist, where lower level pilot experiments are scaled up to change the top down policy making. As indicated in Table 2, the translation methods reviewed are largely oriented toward one or the other of these 
perspectives, with none being ideal for both, and therefore we recommend a mixed methods approach for hybrid cases

\subsection{Extensibility}

Many of the scenario translation methods can also be useful to the stakeholder-driven process of constructing the narrative scenario and/or a model-based process of scenario quantification. Explicitly graphical methods, such as SD and FCM, can jointly engage experts and stakeholders in the process of envisioning and defining narrative scenarios (Mavrommati et al., 2014; Schmitt Olabisi et al., 2010; Yu et al., 2011). Methods emphasizing individual decision-making, such as agent-based modeling and role playing games, can help in identifying larger scale emergent patterns needed to distinguish diverse scenarios (Gerst et al., 2013).

Process-based translation methods, including system dynamics and agent-based modeling, can be fully parameterized to generate simulations that quantify the scenarios of interest. Similarly, graphical methods of reasoning, such as fuzzy cognitive maps and Bayesian networks, can be specified numerically using empirical or subjective reasoning under uncertainty. These then yield scenario quantifications that account for lack of knowledge and/or inherent risk.

The more nonrepresentational methods, including fuzzy sets, pairwise comparison, and Bayesian reasoning, are useful primarily for translating between qualitative narratives and quantitative models developed by other means. Similarly, surveys, interviews, and literature review are not particularly extensible beyond the purposes of translation (Table 2).

\subsection{Type of Participation}

Too often, the task of translating narrative scenarios to quantitative model formulations and inputs has been left to technical modelers. Yet, as indicated in Table 2, most of the translation methods reviewed here are appropriately applied when experts and stakeholders work cooperatively. The participation of a broad base of experts across particular areas of expertise or disciplines expands the range of methods that could be used. Likewise, stakeholder involvement is essential for successful application of some translation methods, including role-playing games, surveys, and interviews. Other methods, including system dynamics, agent-based modeling, fuzzy cognitive maps, fuzzy sets, and Bayesian networks, can accommodate stakeholder participation, and especially benefit from experts and stakeholders working together. Because of their complexity, methods that require probabilistic reasoning need to engage stakeholders in innovative ways, such as participatory modeling with Bayesian networks (Henriksen et 
al., 2007; Meyer et al., 2014; Zorrilla et al., 2010). Still other methods, like literature reviews offer no opportunity for stakeholder engagement.

Scenario translation can serve as an opportunity for researchers and stakeholders to exchange points of view. Yet, the time, effort, conflict resolution, and communication skills demanded of a participatory approach to scenario translation may make the transaction costs too much to bear (Sayer et al., 2013). Some stakeholders may also have difficulty understanding scenarios and models (Becu et al., 2008) and, therefore, the translation process. Field studies have revealed the importance of stakeholder understanding of the method for them to trust it and use it beyond lip service. Modelers who plan to engage stakeholders in scenario translation ought to take the time to learn from existing best practices in participatory modeling, including flexibility, temporal and spatial openness, and transparency (Voinov and Bousquet, 2010).

\subsection{Compatible Model Types}

As described in the sub-section on extensibility above, some translation methods can either be used directly as quantitative models (e.g., system dynamics, agent-based, fuzzy cognitive maps, and Bayesian networks) or are naturally paired with certain model methodologies (e.g., fuzzy cognitive maps and system dynamics, Bayesian reasoning and statistical models, or role-playing games and agent-based models). Others, including fuzzy sets, pairwise comparison, surveys and interviews, and literature review can be used with most, if not all, types of simulation models.

\section{Conclusions}

Our review of methods for translating between narrative and quantitative scenarios, including the guidance given in Table 2, should allow those involved in the scenario development process to choose a method appropriate to their scale, purpose, level of participation, and project resources. For example, one can see from Table 2 that if the goal of a project is to explore the outcomes of lower-level land-use decisions by developing both qualitative and quantitative scenarios in a combined expert/stakeholder workshop setting, then agent-based modeling may be the best choice. If, on the other hand, the goal is to explore higher-level, top-down policies by developing a quantitative model informed primarily by experts, then system dynamics, fuzzy cognitive maps, or Bayesian networks would be most appropriate. A mixed methods approach is most appropriate in situations of a hybrid case, where lower level pilot experiments are scaled up to inform the top down policy making. The table also reveals that relying on the existing literature alone, often the default approach for many modelers, may not be the optimal scenario translation choice given the study objectives. 
Practically, in some situations it may be best to combine multiple options in a mixed methods approach. In the PRELUDE project, for example, stakeholders developed influence diagrams of the main drivers in the narratives and determined a subjective magnitude of change for each of the drivers (Volkery et al., 2008). These qualitative values were subsequently translated into a numerical value based on existing scenarios and past data. Hence, literature reviews and semi-structured interviews were used in combination with Bayesian networks and a variation of fuzzy cognitive maps to quantify narratives. We expect such creative exploitation of the individual advantages of many of the methods reviewed here to be a practical approach for many real-world assessments of land use change going forward.

\section{Acknowledgements}

This research was supported in part by the Scenarios Society and Solutions Research Coordination Network (Grant No. NSF-DEB-13-38809). We thank Kathy Fallon Lambert and Katie Theoharides for their efforts leading the $\mathrm{S}^{3} \mathrm{RCN}$ and organizing the Scenarios to Simulation workshop in Hanover, NH in February, 2015. We appreciate the expertise and involvement of the workshop participants. Additional support was provided by the National Science Foundation through the New Hampshire Experimental Program to Stimulate Cooperative Research (NH EPSCoR) Ecosystems and Society Project. We also thank Cameron Wake, Alexandra Thorn, Curt Grim, Barbara Wauchope and Clay Mitchell for providing the scenarios from the Ecosystems and Society Project for use in the workshop. 


\section{References}

Aalders, I., 2008. Modeling land-use decision behavior with Bayesian belief networks. Ecology and Society 13(1) 16.

Abildtrup, J., Audsley, E., Fekete-Farkas, M., Giupponi, C., Gylling, M., Rosato, P., Rounsevell, M., 2006. Socio-economic scenario development for the assessment of climate change impacts on agricultural land use: a pairwise comparison approach. Environmental Science \& Policy 9(2) 101115.

Ahlqvist, O., 2004. A parameterized representation of uncertain conceptual spaces. Transactions in GIS 8(4) 493-514.

Alcamo, J., 2009. The SAS Approach: Combining Qualitative and Quantitative Knowledge in Environmental Scenarios, In: Joseph, A. (Ed.), Environmetal Futures. The Practice of Environmental Scenario Analysis. Elsevier, pp. 123-150.

Alcamo, J., Acosta-Michlik, L., Carius, A., Eierdanz, F., Klein, R., Krömker, D., Tänzler, D., 2008. A new approach to quantifying and comparing vulnerability to drought. Regional Environmental Change 8(4) 137-149.

Barnaud, C., Van Paassen, A., Trebuil, G., Promburom, T., Bousquet, F., 2010. Dealing with power games in a companion modelling process: lessons from community water management in Thailand highlands. Journal of agricultural education and extension 16(1) 55-74.

Barreteau, O., Antona, M., d'Aquino, P., Aubert, S., Boissau, S., Bousquet, F., Daré, W., Etienne, M., Le Page, C., Mathevet, R., 2003. Our companion modelling approach. Journal of Artificial Societies and Social Simulation 6(2) 1.

Barreteau, O., Bousquet, F., Attonaty, J.-M., 2001. Role-playing games for opening the black box of multi-agent systems: method and lessons of its application to Senegal River Valley irrigated systems. Journal of Artificial Societies and Social Simulation 4(2) 5.

Barton, D.N., Kuikka, S., Varis, O., Uusitalo, L., Henriksen, H.J., Borsuk, M., de la Hera, A., Farmani, R., Johnson, S., Linnell, J.D., 2012. Bayesian networks in environmental and resource management. Integrated environmental assessment and management 8(3) 418-429.

Becu, N., Neef, A., Schreinemachers, P., Sangkapitux, C., 2008. Participatory computer simulation to support collective decision-making: Potential and limits of stakeholder involvement. Land Use Policy 25(4) 498-509.

Borsuk, M.E., Stow, C.A., Reckhow, K.H., 2004. A Bayesian network of eutrophication models for synthesis, prediction, and uncertainty analysis. Ecological Modelling 173(2) 219-239.

Bousquet, F., Barreteau, O., Le Page, C., Mullon, C., Weber, J., 1999. An environmental modelling approach: the use of multi-agent simulations, In: Blasco, F., Weil, A. (Eds.), Advances in Environmental and Ecological Modelling. Elsevier: Paris, pp. 113-122.

Campbell, D.J., Palutikof, J., 1978. Allocation of land resources in semi-arid areas: a simulation based on the East African experience. Discussion Paper 262, Nairobi: Institute for Development Studies, University of Nairobi.

Carpenter, S.R., Booth, E.G., Gillon, S., Kucharik, C.J., Loheide, S., Mase, A.S., Motew, M., Qiu, J., Rissman, A.R., Seifert, J., 2015. Plausible futures of a social-ecological system: Yahara watershed, Wisconsin, USA. Ecology and Society 20(2) 10.

Cash, D., Clark, W.C., Alcock, F., Dickson, N.M., Eckley, N., Jäger, J., 2002. Salience, credibility, legitimacy and boundaries: Linking research, assessment and decision making, Harvard University. 
Castella, J.-C., Kam, S.P., Quang, D.D., Verburg, P.H., Hoanh, C.T., 2007. Combining top-down and bottom-up modelling approaches of land use/cover change to support public policies: Application to sustainable management of natural resources in northern Vietnam. Land Use Policy 24(3) 531-545.

Castella, J.-C., Trung, T.N., Boissau, S., 2005. Participatory simulation of land-use changes in the northern mountains of Vietnam: the combined use of an agent-based model, a role-playing game, and a geographic information system. Ecology and Society 10(1) 27.

Commere, R., 1989. Le développement local en milieu rural. 221 p. Université de Saint.

Cornelissen, A., Van den Berg, J., Koops, W., Grossman, M., Udo, H., 2001. Assessment of the contribution of sustainability indicators to sustainable development: a novel approach using fuzzy set theory. Agriculture, Ecosystems \& Environment 86(2) 173-185.

D'Aquino, P., Barreteau, O., Etienne, M., Boissau, S., Aubert, S., Bousquet, F., Le Page, C., Daré, W., 2002. The Role Playing Games in an ABM participatory modeling process: outcomes from five different experiments carried out in the last five years, Integrated assessment and decision support. iEMSs. 1st Biennial Meeting of the International Environmental Modelling and Software Society, Lugano, Switzerland, pp. 24-27.

D'Aquino, P., Le Page, C., Bousquet, F., Bah, A., 2003. Using self-designed role-playing games and a multi-agent system to empower a local decision-making process for land use management: The SelfCormas experiment in Senegal. Journal of Artificial Societies and Social Simulation 6(3).

Diniz, F.H., Kok, K., Hoogstra-Klein, M.A., Arts, B., 2015. Mapping future changes in livelihood security and environmental sustainability based on perceptions of small farmers in the Brazilian Amazon. Ecology and Society 20(2) 26.

Dubrovsky, M., Simon, K., Stuch, B., Kok, K., Harrison, P., 2011. Report on the European driving force database for use in the Integrated Assessment Platform, The CLIMSAVE Project Climate Change Integrated Assessment Methodology for Cross-sectoral Adaptation and Vulnerability in Europe.

Dumrongrojwatthana, P., Le Page, C., Gajaseni, N., Trébuil, G., 2011. Co-constructing an agent-based model to mediate land use conflict between herders and foresters in northern Thailand. Journal of Land Use Science 6(2-3) 101-120.

Dung, L., Hoanh, C.T., Le Page, C., Bousquet, F., Gajaseni, N., 2009. Facilitating dialogue between aquaculture and agriculture: lessons from role-playing games with farmers in the Mekong Delta, Vietnam. Water Policy 11 80-93.

Etienne, M., Du Toit, D.R., Pollard, S., 2011. ARDI: a co-construction method for participatory modeling in natural resources management. Ecology and Society 16(1) 44.

Ford, F.A., 1999. Modeling the environment: an introduction to system dynamics models of environmental systems. Island Press, Washington, DC.

Gerst, M., Wang, P., Borsuk, M., 2013. Discovering plausible energy and economic futures under global change using multidimensional scenario discovery. Environmental Modelling \& Software 44 76-86.

Geyer-Schulz, A., 1995. Fuzzy Rule-Based Expert Systems and Genetic Machine Learning. PhysicaVerlag, Heidelberg.

Goguen, J.A., 1969. The logic of inexact concepts. Synthese 19(3) 325-373.

Gray, S.A., Gray, S., De Kok, J.L., Helfgott, A.E., O'Dwyer, B., Jordan, R., Nyaki, A., Analyzing, F., 2015. Using fuzzy cognitive mapping as a participatory approach to analyze change, preferred states, and perceived resilience of social-ecological systems. Ecology and Society 20(2) 11. 
Houet, T., Aguejdad, R., Doukari, O., Battaia, G., Clarke, K., 2016. Description and validation of a "non path-dependent" model for projecting contrasting urban growth futures. Cybergeo: European Journal of Geography.

Janssen, M.A., 2005. Agent-based modelling. Modelling in Ecological Economics 1 155-172.

Jensen, F.V., 2001. Bayesian networks and decision graphs. Statistics for Engineering and Information Science, 2 ed. Springer, Verlag New York.

Jetter, A.J., Kok, K., 2014. Fuzzy Cognitive Maps for futures studies-A methodological assessment of concepts and methods. Futures 61 45-57.

Kelly, R.A., Jakeman, A.J., Barreteau, O., Borsuk, M.E., ElSawah, S., Hamilton, S.H., Henriksen, H.J., Kuikka, S., Maier, H.R., Rizzoli, A.E., 2013. Selecting among five common modelling approaches for integrated environmental assessment and management. Environmental Modelling \& Software 47 $159-181$.

Kemp-Benedict, E., 2006. Narrative-led and indicator-driven scenario development. a methodology for constructing scenarios, Scenario Analysis. A Tool for Task Managers, version, 1.

Kemp-Benedict, E., 2010. Converting qualitative assessments to quantitative assumptions: Bayes' rule and the pundit's wager. Technological Forecasting and Social Change 77(1) 167-171.

Kemp-Benedict, E., 2013. Going from Narrative to Number: Indicator-Driven Scenario Quantification, Recent Developments in Foresight Methodologies. Springer: New York, pp. 123-131.

Kok, K., 2009. The potential of Fuzzy Cognitive Maps for semi-quantitative scenario development, with an example from Brazil. Global Environmental Change 19(1) 122-133.

Kok, K., Bärlund, I., Flörke, M., Holman, I., Gramberger, M., Sendzimir, J., Stuch, B., Zellmer, K., 2015. European participatory scenario development: strengthening the link between stories and models. Climatic Change 128(3-4) 187-200.

Kosko, B., 1986. Fuzzy cognitive maps. International Journal of Man-Machine Studies 24(1) 65-75.

Lamarque, P., Artaux, A., Barnaud, C., Dobremez, L., Nettier, B., Lavorel, S., 2013. Taking into account farmers' decision making to map fine-scale land management adaptation to climate and socioeconomic scenarios. Landscape and Urban Planning 119 147-157.

Le Page, C., Naivinit, W., Trébuil, G., Gajaseni, N., 2014. Companion modelling with rice farmers to characterise and parameterise an agent-based model on the land/water use and labour migration in northeast Thailand, Empirical Agent-Based Modelling-Challenges and Solutions. Springer, pp. 207221.

Ligmann-Zielinska, A., Jankowski, P., 2007. Agent-based models as laboratories for spatially explicit planning policies. Environment and Planning B-Planning \& Design 34(2) 316-335.

Lucieer, A., Kraak, M.-J., 2004. Interactive and visual fuzzy classification of remotely sensed imagery for exploration of uncertainty. International Journal of Geographical Information Science 18(5) 491-512.

Marcot, B.G., Holthausen, R.S., Raphael, M.G., Rowland, M.M., Wisdom, M.J., 2001. Using Bayesian belief networks to evaluate fish and wildlife population viability under land management alternatives from an environmental impact statement. Forest Ecology and Management 153(1) 29-42.

Marcot, B.G., Steventon, J.D., Sutherland, G.D., McCann, R.K., 2006. Guidelines for developing and updating Bayesian belief networks applied to ecological modeling and conservation. Canadian Journal of Forest Research 36(12) 3063-3074.

Martin, G., Felten, B., Duru, M., 2011. Forage rummy: A game to support the participatory design of adapted livestock systems. Environmental Modelling \& Software 26(12) 1442-1453. 
Mavrommati, G., Baustian, M., Dreelin, E., 2014. Coupling Socioeconomic and Lake Systems for Sustainability: A Conceptual Analysis Using Lake St. Clair Region as a Case Study. AMBIO 43(3) 275-287.

McDaniels, T., Mills, T., Gregory, R., Ohlson, D., 2012. Using expert judgments to explore robust alternatives for forest management under climate change. Risk Analysis 32 2098-2112.

Meadows, D., Fiddaman, T., Shannon, D., 1989. Fish banks. Institute for Policy and Social Science Research. Durham: University of New Hampshire.

Meyer, S.R., Johnson, M.L., Lilieholm, R.J., Cronan, C.S., 2014. Development of a stakeholder-driven spatial modeling framework for strategic landscape planning using Bayesian networks across two urban-rural gradients in Maine, USA. Ecological Modelling 291 42-57.

Millennium Ecosystem Assessment, 2003. Ecosystems and human well-being: A framework for assessment, Millenium Ecosystem Assessment: Ecosystems and human well-being. World Resources Institute: Washington, p. 266.

Morgan, M.G., Henrion, M., Small, M., 1992. Uncertainty: a guide to dealing with uncertainty in quantitative risk and policy analysis. Cambridge University Press, Cambridge, UK.

Naivinit, W., Le Page, C., Trébuil, G., Gajaseni, N., 2010. Participatory agent-based modeling and simulation of rice production and labor migrations in Northeast Thailand. Environmental Modelling \& Software 25(11) 1345-1358.

Nakicenovic, N., Swart, R., 2000. Special report on emissions scenarios. Edited by Nebojsa Nakicenovic and Robert Swart, pp. 612. Cambridge, UK: Cambridge University Press. 1.

Onigkeit, J., Lübkert, B., Alcamo, J., 2007. Quantitative model drivers for the GLOWA Jordan River scenarios. Center for Environmental Systems Research. Kurt-Wolters Strasse 3.

Pak, M.V., Brieva, D.C., 2010. Designing and implementing a role-playing game: a tool to explain factors, decision making and landscape transformation. Environmental Modelling \& Software 25(11) $1322-1333$.

Parker, D.C., Berger, T., Manson, S.M., Use, L., 2002. Agent-based models of land-use and land-cover change: report and review of an international workshop, October 4-7, 2001, Irvine, California, USA. LUCC Focus 1 Office.

Parker, D.C., Entwisle, B., Rindfuss, R.R., Vanwey, L.K., Manson, S.M., Moran, E., An, L., Deadman, P., Evans, T.P., Linderman, M., 2008. Case studies, cross-site comparisons, and the challenge of generalization: comparing agent-based models of land-use change in frontier regions. Journal of Land Use Science 3(1) 41-72.

Parker, D.C., Manson, S.M., Janssen, M.A., Hoffmann, M.J., Deadman, P., 2003. Multi-agent systems for the simulation of land-use and land-cover change: A review. Annals of the Association of American Geographers 93(2) 314-337.

Patel, M., Kok, K., Rothman, D.S., 2007. Participatory scenario construction in land use analysis: An insight into the experiences created by stakeholder involvement in the Northern Mediterranean. Land Use Policy 24(3) 546-561.

Pearl, J., 1985. Bayesian networks: A model of self-activated memory for evidential reasoning, 7th Conference of the Cognitive Science Society. Computer Science Department: University of California, Irvine, pp. 329-324.

Promper, C., Puissant, A., Malet, J.-P., Glade, T., 2014. Analysis of land cover changes in the past and the future as contribution to landslide risk scenarios. Applied Geography 53 11-19. 
Rosato, P., Giupponi, C., 2003. What future for Mediterranean agriculture? A proposal to integrate socioeconomics in climate change scenarios, Climate Change in the Mediterranean. Socio-Economic Perspectives of Impacts, Vulnerability and Adaptation. Edward Elgar Publishing Ltd: Cheltenham, UK, pp. 133-158.

Saaty, T.L., 1980. The analytic hierarchy process: planning, priority setting, resources allocation. Mcgraw-Hill McLean, Virginia.

Saaty, T.L., Rogers, P.C., 1976. Higher education in the United States (1985-2000): Scenario construction using a hierarchical framework with eigenvector weighting. Socio-Economic Planning Sciences 10(6) 251-263.

Sayer, J., Sunderland, T., Ghazoul, J., Pfund, J.-L., Sheil, D., Meijaard, E., Venter, M., Boedhihartono, A.K., Day, M., Garcia, C., 2013. Ten principles for a landscape approach to reconciling agriculture, conservation, and other competing land uses. Proceedings of the National Academy of Sciences 110(21) 8349-8356.

Schmitt Olabisi, L.K., Kapuscinski, A.R., Johnson, K.A., Reich, P.B., Stenquist, B., Draeger, K.J., 2010. Using scenario visioning and participatory system dynamics modeling to investigate the future: Lessons from Minnesota 2050. Sustainability 2(8) 2686-2706.

Seppelt, R., Dormann, C.F., Eppink, F.V., Lautenbach, S., Schmidt, S., 2011. A quantitative review of ecosystem service studies: approaches, shortcomings and the road ahead. Journal of Applied Ecology 48(3) 630-636.

Shaftel, F.R., Shaftel, G.A., 1967. Role-Playing for Social Values. John Wiley, New York.

Sleeter, B.M., Sohl, T.L., Bouchard, M.A., Reker, R.R., Soulard, C.E., Acevedo, W., Griffith, G.E., Sleeter, R.R., Auch, R.F., Sayler, K.L., 2012. Scenarios of land use and land cover change in the conterminous United States: utilizing the special report on emission scenarios at ecoregional scales. Global Environmental Change 22(4) 896-914.

Sohl, T.L., Sayler, K.L., Bouchard, M.A., Reker, R.R., Friesz, A.M., Bennett, S.L., Sleeter, B.M., Sleeter, R.R., Wilson, T., Soulard, C., 2014. Spatially explicit modeling of 1992-2100 land cover and forest stand age for the conterminous United States. Ecological Applications 24(5) 1015-1036.

Souchère, V., Millair, L., Echeverria, J., Bousquet, F., Le Page, C., Etienne, M., 2010. Co-constructing with stakeholders a role-playing game to initiate collective management of erosive runoff risks at the watershed scale. Environmental Modelling \& Software 25(11) 1359-1370.

Sterman, J.D., 2000. Business dynamics: systems thinking and modeling for a complex world. McGrawHill, Irwin, Boston.

Sterman, J.D., 2012. Sustaining sustainability: creating a systems science in a fragmented academy and polarized world, Sustainability Science. Springer: New York, pp. 21-58.

Strager, M.P., Rosenberger, R.S., 2006. Incorporating stakeholder preferences for land conservation: Weights and measures in spatial MCA. Ecological Economics 58(1) 79-92.

Swart, R.J., Raskin, P., Robinson, J., 2004. The problem of the future: sustainability science and scenario analysis. Global Environmental Change 14(2) 137-146.

Thompson, J.R., Wiek, A., Swanson, F.J., Carpenter, S.R., Fresco, N., Hollingsworth, T., Spies, T.A., Foster, D.R., 2012. Scenario studies as a synthetic and integrative research activity for long-term ecological research. BioScience 62(4) 367-376.

Uusitalo, L., 2007. Advantages and challenges of Bayesian networks in environmental modelling. Ecological Modelling 203(3) 312-318. 
van Vliet, M., Kok, K., Veldkamp, T., 2010. Linking stakeholders and modellers in scenario studies: The use of Fuzzy Cognitive Maps as a communication and learning tool. Futures 42(1) 1-14.

Verburg, P.H., Overmars, K.P., 2009. Combining top-down and bottom-up dynamics in land use modeling: exploring the future of abandoned farmlands in Europe with the Dyna-CLUE model. Landscape Ecology 24(9) 1167-1181.

Voinov, A., Bousquet, F., 2010. Modelling with stakeholders. Environmental Modelling \& Software 25(11) 1268-1281.

Volkery, A., Ribeiro, T., Henrichs, T., Hoogeveen, Y., 2008. Your vision or my model? Lessons from participatory land use scenario development on a European scale. Systemic Practice and Action Research 21(6) 459-477.

Washington-Ottombre, C., Pijanowski, B., Campbell, D., Olson, J., Maitima, J., Musili, A., Kibaki, T., Kaburu, H., Hayombe, P., Owango, E., 2010. Using a role-playing game to inform the development of land-use models for the study of a complex socio-ecological system. Agricultural Systems 103(3) 117-126.

Welp, M., de la Vega-Leinert, A., Stoll-Kleemann, S., Jaeger, C.C., 2006. Science-based stakeholder dialogues: Theories and tools. Global Environmental Change 16(2) 170-181.

Yu, W., Zang, S., Wu, C., Liu, W., Na, X., 2011. Analyzing and modeling land use land cover change (LUCC) in the Daqing City, China. Applied Geography 31(2) 600-608.

Zadeh, L.A., 1965. Fuzzy sets. Information and Control 8(3) 338-353.

Zimmermann, H.J., 2010. Fuzzy set theory. Wiley Interdisciplinary Reviews: Computational Statistics 2(3) $317-332$. 
Table 1: Summary of Translation Methods

\begin{tabular}{|c|c|c|c|c|c|c|}
\hline Method & $\begin{array}{l}\text { Conceptual } \\
\text { foundation }\end{array}$ & $\begin{array}{l}\text { Treatment of } \\
\text { Uncertainty }\end{array}$ & $\begin{array}{l}\text { Potential for } \\
\text { Stakeholder } \\
\text { Participation }\end{array}$ & $\begin{array}{l}\text { Level of } \\
\text { Resources/Time } \\
\text { Required }\end{array}$ & $\begin{array}{l}\text { Compatibility with } \\
\text { Simulation Models }\end{array}$ & $\begin{array}{l}\text { Example } \\
\text { References }\end{array}$ \\
\hline $\begin{array}{l}\text { System } \\
\text { Dynamics } \\
\text { (Causal Loop } \\
\text { Diagrams) }\end{array}$ & $\begin{array}{l}\text { Systems' thinking: } \\
\text { mapping positive } \\
\text { and negative } \\
\text { feedback loops } \\
\text { between system } \\
\text { parameters }\end{array}$ & Sensitivity analysis & $\begin{array}{l}\text { Very suitable for } \\
\text { stakeholder } \\
\text { engagement, with } \\
\text { participation } \\
\text { facilitated through } \\
\text { workshops. }\end{array}$ & $\begin{array}{l}\text { An iterative process } \\
\text { with the level of } \\
\text { resources and time } \\
\text { involvement } \\
\text { depending on the level } \\
\text { of stakeholders' } \\
\text { participation and the } \\
\text { research objective. }\end{array}$ & $\begin{array}{l}\text { Causal loop diagrams } \\
\text { are often used as a basis } \\
\text { for building stock-flow } \\
\text { models. Stand-alone } \\
\text { CLDs can also be used } \\
\text { to understand leverage } \\
\text { points for policy } \\
\text { intervention. }\end{array}$ & $\begin{array}{l}\text { (Mavrommati et } \\
\text { al., 2014; } \\
\text { Schmitt Olabisi } \\
\text { et al., 2010; } \\
\text { Sterman, 2000) }\end{array}$ \\
\hline $\begin{array}{l}\text { Agent-Based } \\
\text { Modeling }\end{array}$ & $\begin{array}{l}\text { Exploratory tool to } \\
\text { understand the } \\
\text { effects of micro- } \\
\text { level agent } \\
\text { behaviors on } \\
\text { macro-level } \\
\text { phenomenon }\end{array}$ & $\begin{array}{l}\text { Sensitivity analysis } \\
\text { or Monte Carlo } \\
\text { simulation }\end{array}$ & $\begin{array}{l}\text { Suitable for } \\
\text { stakeholder } \\
\text { engagement, with } \\
\text { participation } \\
\text { facilitated through } \\
\text { workshops. }\end{array}$ & $\begin{array}{l}\text { An iterative process } \\
\text { with the level of } \\
\text { resources and time } \\
\text { involvement } \\
\text { depending on the level } \\
\text { of stakeholders' } \\
\text { participation and the } \\
\text { research objective. }\end{array}$ & $\begin{array}{l}\text { Agent based causal } \\
\text { diagrams are used as a } \\
\text { basis for constructing } \\
\text { agent based models. } \\
\text { Stand-alone causal } \\
\text { diagrams can also be } \\
\text { used to understand } \\
\text { leverage points for } \\
\text { policy intervention }\end{array}$ & $\begin{array}{l}\text { (Janssen, 2005; } \\
\text { Parker et al., } \\
\text { 2003) }\end{array}$ \\
\hline $\begin{array}{l}\text { Fuzzy } \\
\text { Cognitive } \\
\text { Maps }\end{array}$ & $\begin{array}{l}\text { Fuzzy logic; } \\
\text { mapping feedback } \\
\text { loops representing } \\
\text { strength of a causal } \\
\text { relationship } \\
\text { between system } \\
\text { variables }\end{array}$ & $\begin{array}{l}\text { The treatment of } \\
\text { uncertainty is } \\
\text { inherent. Diverse or } \\
\text { uncertain } \\
\text { judgments about } \\
\text { causal relationships } \\
\text { are represented as a } \\
\text { fuzzy set or } \\
\text { membership } \\
\text { function }\end{array}$ & $\begin{array}{l}\text { Very suitable for } \\
\text { stakeholder } \\
\text { engagement, with } \\
\text { participation } \\
\text { facilitated through } \\
\text { workshops. }\end{array}$ & $\begin{array}{l}\text { An iterative process } \\
\text { with the level of } \\
\text { resources and time } \\
\text { involvement } \\
\text { depending on the level } \\
\text { of stakeholders' } \\
\text { participation and the } \\
\text { research objective. }\end{array}$ & $\begin{array}{l}\text { The FCM itself can be } \\
\text { simulated after strength } \\
\text { of causal relationships } \\
\text { are identified. }\end{array}$ & $\begin{array}{l}\text { (Patel et al.; van } \\
\text { Vliet et al., 2010) }\end{array}$ \\
\hline
\end{tabular}




\begin{tabular}{|c|c|c|c|c|c|c|}
\hline Fuzzy Sets & $\begin{array}{l}\text { Fuzzy logic; } \\
\text { variables are } \\
\text { represented as a } \\
\text { fuzzy view of } \\
\text { diverse judgments }\end{array}$ & $\begin{array}{l}\text { The treatment of } \\
\text { uncertainty is } \\
\text { inherent. Diverse } \\
\text { or uncertain } \\
\text { judgments about } \\
\text { variables are } \\
\text { represented as a } \\
\text { fuzzy set or } \\
\text { membership } \\
\text { function }\end{array}$ & $\begin{array}{l}\text { Very suitable for } \\
\text { stakeholder } \\
\text { engagement in } \\
\text { multiple forms. It is } \\
\text { an easy method to } \\
\text { teach to stakeholders }\end{array}$ & $\begin{array}{l}\text { The method is simple } \\
\text { and multiple iterations } \\
\text { can be executed in a } \\
\text { single workshop. }\end{array}$ & $\begin{array}{l}\text { The fuzzy numerical } \\
\text { output can be used } \\
\text { directly as inputs to } \\
\text { stochastic models or } \\
\text { defuzzified for non- } \\
\text { stochastic models. }\end{array}$ & $\begin{array}{l}\text { (Alcamo, 2009; } \\
\text { Dubrovsky et al., } \\
\text { 2011; Kok et al., } \\
\text { 2015) }\end{array}$ \\
\hline $\begin{array}{l}\text { Pairwise } \\
\text { Comparison }\end{array}$ & $\begin{array}{l}\text { Pairwise } \\
\text { comparison of } \\
\text { storylines followed } \\
\text { by translation of } \\
\text { qualitative } \\
\text { evaluations into } \\
\text { numerical values. }\end{array}$ & $\begin{array}{l}\text { Sensitivity analysis } \\
\text { based on the } \\
\text { diversity of expert } \\
\text { judgments }\end{array}$ & $\begin{array}{l}\text { Suitable for } \\
\text { stakeholder } \\
\text { engagement, with } \\
\text { participation } \\
\text { facilitated through } \\
\text { workshops. }\end{array}$ & $\begin{array}{l}\text { Analytic hierarchy } \\
\text { process is time } \\
\text { consuming and needs } \\
\text { several iterations } \\
\text { before evaluations } \\
\text { across all experts } \\
\text { become consistent. }\end{array}$ & $\begin{array}{l}\text { Provides direct input } \\
\text { for a simulation model. }\end{array}$ & $\begin{array}{l}\text { (Abildtrup et al., } \\
\text { 2006; McDaniels } \\
\text { et al., 2012) }\end{array}$ \\
\hline $\begin{array}{l}\text { Bayesian } \\
\text { Reasoning }\end{array}$ & $\begin{array}{l}\text { Bayesian reasoning } \\
\text { through } \\
\text { specification of a } \\
\text { prior distribution } \\
\text { (based on a } \\
\text { baseline scenario) } \\
\text { and likelihood } \\
\text { distribution (based } \\
\text { on plausible } \\
\text { scenario). }\end{array}$ & $\begin{array}{l}\text { The treatment of } \\
\text { uncertainty is } \\
\text { inherent. The } \\
\text { inputs and outputs } \\
\text { are both probability } \\
\text { distributions. }\end{array}$ & $\begin{array}{l}\text { It requires some } \\
\text { degree of specialized } \\
\text { knowledge for } \\
\text { effective stakeholder } \\
\text { participation and to } \\
\text { find innovative ways } \\
\text { to do so. }\end{array}$ & $\begin{array}{l}\text { Depends on the } \\
\text { objective and number } \\
\text { of experts involved in } \\
\text { the process. } \\
\text { Deliberative } \\
\text { assessments among } \\
\text { experts can make the } \\
\text { process time- } \\
\text { consuming }\end{array}$ & $\begin{array}{l}\text { Provides direct input to } \\
\text { stochastic simulation } \\
\text { models. }\end{array}$ & $\begin{array}{l}\text { (Kemp-Benedict, } \\
\text { 2013) }\end{array}$ \\
\hline $\begin{array}{l}\text { Bayesian } \\
\text { Networks }\end{array}$ & $\begin{array}{l}\text { Influence diagrams } \\
\text { map dependence } \\
\text { among variables. } \\
\text { Conditional } \\
\text { probabilities quanti } \\
\text { fy the strength of } \\
\text { the dependences. }\end{array}$ & $\begin{array}{l}\text { The treatment of } \\
\text { uncertainty is } \\
\text { inherent; } \\
\text { conditional } \\
\text { probability } \\
\text { distributions }\end{array}$ & $\begin{array}{l}\text { This method is } \\
\text { suitable for } \\
\text { stakeholder } \\
\text { engagement, but it } \\
\text { requires stakeholders } \\
\text { to understand the } \\
\text { concept of } \\
\text { conditional } \\
\text { probabilities. }\end{array}$ & $\begin{array}{l}\text { Depends on the scale } \\
\text { and objective of the } \\
\text { study. It can be a time- } \\
\text { intensive process if } \\
\text { conditional } \\
\text { probabilities are } \\
\text { continuously updated } \\
\text { based on new } \\
\text { evidence. }\end{array}$ & $\begin{array}{l}\text { Influence diagrams and } \\
\text { CPTs lead to functional } \\
\text { Bayesian Networks, } \\
\text { which themselves may } \\
\text { lead to inputs for other } \\
\text { models. }\end{array}$ & $\begin{array}{l}\text { (Aalders, 2008; } \\
\text { Marcot et al., } \\
\text { 2006) }\end{array}$ \\
\hline
\end{tabular}




\begin{tabular}{|c|c|c|c|c|c|c|}
\hline $\begin{array}{l}\text { Role Playing } \\
\text { Games }\end{array}$ & $\begin{array}{l}\text { A combined } \\
\text { representation of } \\
\text { qualitative } \\
\text { storylines and the } \\
\text { local decision } \\
\text { making processes } \\
\text { in the form of a } \\
\text { game }\end{array}$ & $\begin{array}{l}\text { Not generally } \\
\text { applicable. }\end{array}$ & $\begin{array}{l}\text { Stakeholder } \\
\text { engagement is } \\
\text { essential for this } \\
\text { method, whose } \\
\text { participation is } \\
\text { facilitated through } \\
\text { workshops. }\end{array}$ & $\begin{array}{l}\text { Depends on the } \\
\text { number of stakeholders } \\
\text { involved and the } \\
\text { objective of the study. } \\
\text { Consensus and trust } \\
\text { building exercises can } \\
\text { be time consuming and } \\
\text { resource intensive }\end{array}$ & $\begin{array}{l}\text { Stakeholders' decisions } \\
\text { during the game can } \\
\text { serve as inputs to } \\
\text { simulation models. } \\
\text { Stand-alone RPGs can } \\
\text { also produce } \\
\text { quantitative maps of } \\
\text { land use change. }\end{array}$ & $\begin{array}{l}\text { (Castella et al., } \\
\text { 2005; Lamarque } \\
\text { et al., 2013) }\end{array}$ \\
\hline $\begin{array}{l}\text { Surveys or } \\
\text { Semi- } \\
\text { Structured } \\
\text { Interviews }\end{array}$ & $\begin{array}{l}\text { A survey of } \\
\text { subjective beliefs of } \\
\text { experts or } \\
\text { stakeholders. }\end{array}$ & $\begin{array}{l}\text { Depends on the } \\
\text { way parameters are } \\
\text { elicited. } \\
\text { Uncertainty can be } \\
\text { inherent if } \\
\text { elicitations are } \\
\text { probabilistic, } \\
\text { otherwise } \\
\text { sensitivity analysis } \\
\text { based on the } \\
\text { diversity of } \\
\text { judgments can be } \\
\text { performed. }\end{array}$ & $\begin{array}{l}\text { This method can } \\
\text { allow stakeholder } \\
\text { engagement. }\end{array}$ & $\begin{array}{l}\text { Depends on the way } \\
\text { the survey is } \\
\text { conducted. This } \\
\text { method can be time } \\
\text { and resource intensive } \\
\text { if a semi-structured } \\
\text { interview process is } \\
\text { used. If time is a } \\
\text { constraint, a written } \\
\text { survey can be used. }\end{array}$ & $\begin{array}{l}\text { Provides direct inputs } \\
\text { to a simulation model. }\end{array}$ & $\begin{array}{l}\text { (McDaniels, } \\
\text { Mills, Gregory, } \\
\text { \& Ohlson, 2012) }\end{array}$ \\
\hline $\begin{array}{l}\text { Literature } \\
\text { Review }\end{array}$ & $\begin{array}{l}\text { Based on a } \\
\text { literature review, } \\
\text { the modelers' or } \\
\text { experts' } \\
\text { interpretation of } \\
\text { storylines is used to } \\
\text { infer model inputs } \\
\text { and assumptions. } \\
\text { The inference is } \\
\text { usually done by } \\
\text { adapting the } \\
\text { variables for } \\
\text { current projections } \\
\text { to the developed } \\
\text { storylines }\end{array}$ & $\begin{array}{l}\text { Depends on the } \\
\text { way variables are } \\
\text { reported. } \\
\text { Uncertainty can be } \\
\text { inherent if studies } \\
\text { are probabilistic, } \\
\text { otherwise } \\
\text { sensitivity analysis } \\
\text { can be performed. }\end{array}$ & $\begin{array}{l}\text { Not generally } \\
\text { applicable. }\end{array}$ & $\begin{array}{l}\text { Usually not resource } \\
\text { and time intensive. } \\
\text { However, consensus } \\
\text { between narrative } \\
\text { developers and } \\
\text { quantifiers can be hard } \\
\text { to reach and an } \\
\text { iterative process of } \\
\text { communication } \\
\text { between modelers or } \\
\text { experts and } \\
\text { stakeholders can make } \\
\text { the process time- } \\
\text { intensive. }\end{array}$ & $\begin{array}{l}\text { Provides direct input to } \\
\text { a simulation model. }\end{array}$ & $\begin{array}{l}\text { (Promper et al., } \\
\text { 2014; Sohl et al., } \\
\text { 2014) }\end{array}$ \\
\hline
\end{tabular}


Table 2: Decision matrix for choosing a translation method. Subjective rankings (none, low, med, high) correspond to degree of fulfillment of each method with each criterion, with 'high' being the most and 'low' being the least.

\begin{tabular}{|c|c|c|c|c|c|c|c|c|c|c|c|}
\hline & Method & 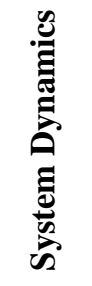 & 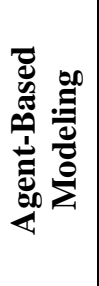 & 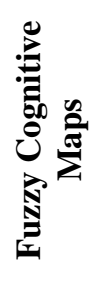 & 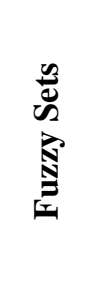 & 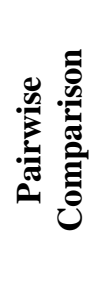 & 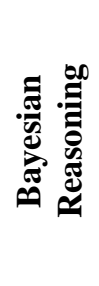 & 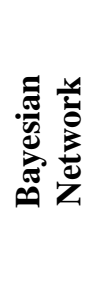 & 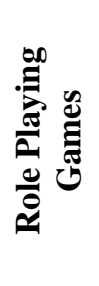 & 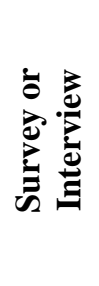 & 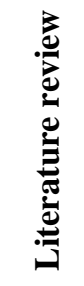 \\
\hline 串 & $\begin{array}{c}\text { Evaluate lower-level } \\
\text { actions and anticipated } \\
\text { outcomes }\end{array}$ & med & high & med & low & low & low & med & high & high & med \\
\hline$\stackrel{\Xi}{\infty}$ & $\begin{array}{l}\text { Evaluate top-down policy } \\
\text { and prescriptive actions }\end{array}$ & high & low & high & high & high & high & high & low & med & med \\
\hline 窟 & $\begin{array}{l}\text { Creating narrative } \\
\text { scenarios }\end{array}$ & high & high & high & none & none & none & med & high & low & low \\
\hline 离 & $\begin{array}{l}\text { Developing quantitative } \\
\text { model-based scenarios }\end{array}$ & high & high & med & low & low & low & high & med & none & none \\
\hline & $\begin{array}{l}\text { Can be performed } \\
\text { independently }\end{array}$ & low & low & none & none & none & med & low & none & none & high \\
\hline 离 & $\begin{array}{l}\text { Can be performed } \\
\text { through expert } \\
\text { collaboration }\end{array}$ & med & med & med & med & med & high & med & none & low & high \\
\hline : & $\begin{array}{c}\text { Can be performed in an } \\
\text { workshop }\end{array}$ & high & high & high & high & high & low & high & high & high & none \\
\hline$E$ & $\begin{array}{l}\text { Can be performed through } \\
\text { stakeholder collaboration }\end{array}$ & med & low & med & med & high & none & med & high & med & none \\
\hline & mpatible model types & 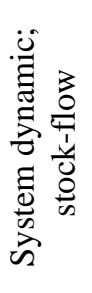 & 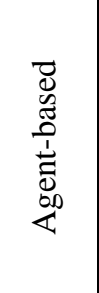 & 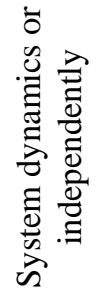 & $\bar{z}$ & $\bar{z}$ & 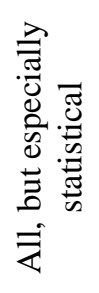 & 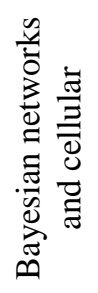 & 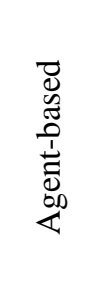 & $\bar{z}$ & $\bar{z}$ \\
\hline
\end{tabular}

